\title{
Analisis Kebangkrutan Pada Perusahaan Perbankan Di Indonesia Periode 2001-2012 \\ (Dengan Menggunakan Model Altman Z-Score)
}

\author{
Aminah \\ Andi Sanjaya \\ (Universitas Bandar Lampung (UBL)) \\ Email: amy_ubl@ymail.com \\ Email:sanjaya350@gmail.com
}

\begin{abstract}
The purpose of this study is to provide empirical evidence about the bankruptcy prediction model used by Altman. Research questions were constructed in this study is whether the Altman Z-Score model that built in 1968 can be used and relied upon in accommodating economic climate in Indonesia, especially as a predictor of bankruptcy in Indonesia banking company. Statistical test results showed that the Altman Z-Score model appropriate for use in predicting the potential bankruptcy of the Indonesia banking company on the observation period 2001-2012. By doing so, this study conclude that the Altman ZScore models can be a tool for predicting bankruptcy in Indonesia.
\end{abstract}

Keywords: Altman Z-Score, Bankruption, Indonesia Banking Corporation.

\section{LATAR BELAKANG}

Industri perbankan selama beberapa kurun waktu belakangan mengalami perkembangan yang pesat. Bank dianggap sebagai penggerak roda perekonomian suatu negara. Hal ini dikarenakan fungsi bank sebagai lembaga keuangan sangat penting, misalnya dalam peredaraan uang guna menunjang kegiatan usaha, tempat menyimpan uang, melakukan pembayaran atau penagihan, pembiayaan, dan masih banyak jasa keuangan lainnya (Kamal, 2012).

Untuk mempertahankan suatu sistem keuangan, sebuah bank harus dapat berkompetisi dengan bank-bank kompetitor dan lembaga penyedia jasa keuangan lainnya yang juga memberikan layanan jasa keuangan. Suatu bank dikatakan berhasil memenangkan kompetisi bisnisnya jika ia mampu memberikan jasa layanan keuangan lebih baik daripada kompetitornya, sekaligus mampu mengadaptasikan diri dengan setiap perubahan lingkungan (Hadad et al, 2004). Guna mengantisipasi hadirnya kesulitan keuangan pada bank, perlu dikembangkan suatu sistem yang dapat memberikan peringatan dini (early warning) adanya problem keuangan yang mengancam kelangsungan operasional bank. Potensi kebangkrutan 
yangterdeteksi dini akan memungkinkan pihak manajemen memberikan penanganan korektif agar dapat memulihkan kondisi keuangan perusahaan dari krisis.

Telah dikembangkan sejumlah model prediksi kesulitan keuangan dan kebangkrutan perusahaan, namun model $Z$ - Score muncul sebagai primadona yang banyak digunakan para pakar ekonomi dunia. Model Z - Score pertama kali diperkenalkan oleh Edward I.Altman dalam bukunya yang berjudul Corporate Financial Distress: A Complete Guide to Predicting, Avoiding, and Dealing With Bancruptcy. Model Z - Score adalah suatu alat yang digunakan untuk meramalkan tingkat kebangkrutan suatu perusahaan dengan menghitung nilai dari beberapa rasio lalu kemudian dimasukkan dalam suatu persamaan diskriminan.(Nurdin, 2012)

Pada tahun 1968 Altman mengembangkan sebuah model prediksi kebangkrutan dengan menggunakan metode MDA (Z-Score) yang memberikan hasil prediksi dengan tingkat akurasi mencapai $95 \%$ pada perusahaan manufaktur yang terdaftar di pasar saham di Amerika Serikat selama satu tahun sebelum mengalami kebangkrutan. Lebih lanjut, dari model awal $Z$ - Score dikembangkan model yang disempurnakan dengan mengambil beberapa sampel perusahaan dengan iklim ekonomi yang berbeda-beda oleh Altman. Model yang disempurnakan ini memberikan hasil prediksi dengan tingkat keakuratan $82 \%$ sampai dengan $85 \%$ dengan memasukkan dimensi internasional di dalam pengujian.

\section{KERANGKA TEORITIS DAN HIPOTESIS}

Analisis diskriminan bermanfaat bagi perusahaan untuk memperoleh peringatan awal kebangkrutan dan kelanjutan usahanya. Semakin awal suatu perusahaan memperoleh peringatan kebangkrutan, semakin baik bagi pihak manajemen karena pihak manajemen bisa melakukan perbaikan-perbaikan dan dapat memberikan gambaran dan harapan yang mantap terhadap nilai masa depan perusahaan tersebut.

Kebangkrutan biasanya diartikan sebagai kegagalan perusahaan dalam menjalankan operasi perusahaan untuk menghasilkan laba. Martin,et. Al, (1995:376) dalam Fakhrurozie (2007:15) mengatakan bahwa kebangkrutan sebagai kegagalan dapat didefinisikan dalam beberapa arti, yaitu :

1) Kegagalan ekonomi (ecomonic distress)

Berarti bahwa perusahaan kehilangan uang atau pendapatan perusahaan tidak menutup biayanya sendiri. Ini berarti tingkat labanya lebih kecil daripada biaya modal atau nilai sekarang dari arus kas perusahaan lebih kecil dari kewajiban. Kegagalan terjadi bila arus kas sebenarnya dari perusahaan tersebut jatuh di bawah arus kas yang diharapkan. 


\section{2) Kegagalan keuangan (financial distress)}

Pengertian financial distressed mempunyai makna kesulitan dana, baik dana dalam pengertian kas atau dalam pengertian modal kerja. Sebagian asset liability management sangat berperan dalam pengaturan untuk menjaga agar tidak terkena financial distressed. Kebangkrutan akan cepat terjadi pada perusahaan yang berada di negara yang sedang mengalami kesulitan ekonomi, karena kesulitan ekonomi akan memicu semakin cepatnya kebangkrutan perusahaan yang mungkin awalnya sudah kurang sehat semakin memburuk dan bangkrut.

Beberapa faktor yang dapat menjadi penyebab kebangkrutan suatu perusahaan adalah sebagai berikut : (Janch \& Glueck, 1995:97) dalam Muhammad Adnan dan Eka Kurniasih (2000: 139).

\section{Faktor umum}

1) Sektor ekonomi

Faktor-faktor penyebab kebangkrutan dari sektor ekonomi adalah gejala inflasi dan deflasi dalam harga barang dan jasa, kebijakan keuangan, suku bunga dan devaluasi atau revaluasi uang dalam hubungannya dengan uang asing serta neraca pembayaran, surplus atau defisit dalam hubungannya dengan perdagangan luar negeri.

2) Sektor sosial

Faktor sosial yang sangat berpengaruh terhadap kebangkrutan cenderung pada perubahan gaya hidup masyarakat yang mempengaruhi permintaan terhadap produk dan jasa ataupun cara perusahaan berhubungan dengan karyawan. Faktor sosial lain yang berpengaruh yaitu kekacauan di masyarakat.

3) Sektor teknologi

Penggunaan teknologi informasi juga menyebabkan biaya yang ditanggung perusahaan membengkak terutama untuk pemeliharaan dan implementasi yang tidak terencana, sistemnya tidak terpadu dan para manajer pengguna kurang profesional.

4) Sektor pemerintah

Kebijakan pemerintah terhadap pencabutan subsidi pada perusahaan dan industri, pengenaan tarif ekspor dan impor barang yang berubah, kebijakan undang-undang baru bagi perbankan atau tenaga kerja dan lain-lain. 


\section{Faktor Eksternal Perusahaan}

1) Sektor pelanggan

Perusahaan harus mengidentifikasi sifat konsumen, untuk menghindari kehilangan konsumen, juga untuk menciptakan peluang, menemukan konsumen baru dan menghindari menurunnya hasil penjualan dan mencegah konsumen berpaling ke pesaing.

2) Sektor pemasok

Perusahaan dan pemasok harus tetap bekerjasama dengan baik karena kekuatan pemasok untuk menaikkan harga dan mengurangi keuntungan pembelinya tergantung pada seberapa besar pemasok ini berhubungan dengan perdagangan bebas.

3) Sektor pesaing

Perusahaan juga jangan melupakan persaingan karena kalau produk pesaing lebih diterima dimasyarakat, maka perusahaan akan kehilangan konsumen dan hal tersebut akan berakibat menurunnya pendapatan perusahaan.

\section{Faktor Internal Perusahaan}

Faktor-faktor ini biasanya merupakan hasil dari keputusan dan kebijakan yang tidak tepat di masa yang lalu dan kegagalan menajemen untuk berbuat sesuatu pada saat yang diperlukan. Seperti terlalu besarnya kredit yang diberikan pelanggan dan manajemen yang tidak efisien.

\subsection{Model Altman Z-Score}

Seperti yang berhasil dikutip dari Kamal (2012), pengertian dari Z-Score adalah skor yang ditentukan dari hitungan standar kali nisbah-nisbah keuangan yang menunjukkan tingkat besaran peluang terjadinya kebangkrutan perusahaan. Formula Z-Score untuk memprediksi kebangkrutan dari Altman merupakan sebuah multivariate formula yang digunakan untuk mengukur kesehatan finansial dari sebuah perusahaan. Altman menemukan lima jenis rasio keuangan yang dapat dikombinasikan untuk melihat perbedaan antara perusahaan yang bangkrut dan yang tidak bangkrut.

Fungsi diskriminan $\mathrm{Z}$ yang ditemukan oleh Altman untuk perusahaan perbankan yang telah go public ditentukan dengan menggunakan rumus sebagai berikut (S.Munawir, 2002: 309):

$Z$-Score $=1,2 \mathrm{X}_{1}+1,4 \mathrm{X}_{2}+3,3 \mathrm{X}_{3}+0,6 \mathrm{X}_{4}+1,0 \mathrm{X}_{5}$

Dimana:

$\mathrm{X}_{1}=$ Working Capital $/$ Total Assets (Modal Kerja/Total Aset) 
$\mathrm{X}_{2}=$ Retained Earning / Total Assets (Laba Ditahan/Total Aset)

$\mathrm{X}_{3}=$ Earning Before Interest and Taxes $($ EBIT) / Total Assets (Pendapatan Sebelum

Dikurangi Biaya Bunga/Total Aset)

$\mathrm{X}_{4}=$ Market Value of Equity / Total Liabilities (Harga Pasar Saham Dibursa/Nilai Total Utang)

$\mathrm{X}_{5}=$ Sales $/$ Total Assets $($ Penjualan/Total Aset)

Dengan interpretasi penilaian sebagai berikut:

a) Z-Score > 2,99 artinya perusahaan tersebut dalam kondisi sehat dan tidak sedang mengalami kesulitan keuangan.

b) 1,81 $<$ Z-Score $<2,99$ artinya perusahaan memiliki peluang mengalami kebangkrutan, namun peluang terselamatkan dan peluang bangkrut sama besarnya, tergantung dari penanganan pihak manajemen dalam mengelola perusahaan mengatasi hal tersebut.

c) Z-Score $<1,81$ artinya perusahaan sedang dalam kondisi mengalami kesulitan keuangan yang pelik dan memiliki peluang besar akan menghadapi kebangkrutan..

Berikut merupakan uraian mengenai rasio-rasio yang kemudian akan dimasukkan ke dalam persamaan diskriminan $Z$ - Score (Kamal, 2012).

a. Modal kerja terhadap total aset (working capital to total assets) digunakan untuk mengukur likuiditas aktiva perusahaan relatif terhadap total kapitalnya atau untuk mengukur kemampuan perusahaan dalam memenuhi kewajiban jangka pendek. Indikator yang dapat digunakan untuk mendeteksi adanya masalah pada tingkat likuiditas perusahaan adalah indikator-indikator internal seperti ketidakcukupan kas, utang dagang membengkak, dan beberapa indikator lainnya.

b. Laba ditahan terhadap total harta (retained earning to total assets) digunakan untuk mengukur profitabilitas kumulatif. Rasio ini mengukur akumulasi laba selama perusahaan beroperasi. Umur perusahaan berpengaruh terhadap rasio tersebut karena semakin lama perusahaan beroperasi memungkinkan untuk memperlancar akumulasi laba ditahan. Hal tersebut dapat menyebabkan perusahaan yang masih relatif muda pada umumnya akan menunjukkan hasil rasio yang rendah, kecuali yang labanya sangat besar pada masa awal berdirinya.

c. Pendapatan sebelum pajak dan bunga terhadap total harta (earnings before interest and taxes to total assets) digunakan untuk mengukur produktivitas yang sebenarnyan dari aktiva perusahaan. Rasio tersebut mengukur kemampuan perusahaan dalam 
menghasilkan laba dari aktiva yang digunakan. Rasio ini merupakan kontributor terbesar dari model tersebut. Beberapa indikator yang dapat kita gunakan dalam mendeteksi adanya masalah pada kemampuan profitabilitas perusahaan diantaranya adalah piutang dagang meningkat, rugi terus-menerus dalam beberapa kwartal, persediaan meningkat, penjualan menurun, dan terlambatnya hasil penagihan piutang.

d. Nilai pasar ekuitas terhadap nilai buku dari utang (market value equity to book value of total debt) digunakan untuk mengukur seberapa banyak aktiva perusahaan dapat turun nilainya sebelum jumlah utang lebih besar daripada aktivanya dan perusahaan menjadi pailit. Modal yang dimaksud adalah gabungan nilai pasar dari modal biasa dan saham preferen, sedangkan utang mencakup utang lancar dan utang jangka panjang.

e. Penjualan terhadap total harta (sales to total assets) digunakan untuk mengukur kemampuan manajemen dalam menghadapi kondisi persaingan. Rasio tersebut mengukur kemampuan manajemen dalam menggunakan aktiva untuk menghasilkan penjualan.

Penelitian di dalam negeri yang telah dilakukan sebelumnya diantaranya dilakukan oleh Endri (2008) yang menganalisis ketepatan model Altman Z-Score dalam memprediksi kebangkrutan pada Bank Umum Syariah selama tiga tahun dari 2005-2007. Variabel yang digunakan model Altman Z-Score untuk perusahaan yang belum go public, yaitu rasio modal kerja / total aktiva $\left(\mathrm{X}_{1}\right)$, laba ditahan / total aktiva $\left(\mathrm{X}_{2}\right)$, EBIT (Earning Before Interest\&Tax) / total aktiva $\left(\mathrm{X}_{3}\right)$, nilai buku saham / nilai buku hutang $\left(\mathrm{X}_{4}\right)$, dan Penjualan / total aktiva $\left(\mathrm{X}_{5}\right)$. Dengan formula $Z=0,717 X_{1}+0,847 X_{2}+3,107 X_{3}+0,420 X_{4}+0,998 X_{5}$. Hasilnya bahwa model Altman Z-Score kurang tepat digunakan untuk memprediksi kebangkrutan pada perbankan syariah.

Kamal (2012) menganalisis prediksi kebangkrutan pada perbankan go public di Bursa Efek Indonesia pada tahun 2008-2010 dengan menggunakan model Altman Z-Score. Variabel yang digunakan model Altman Z-Score yaitu rasio modal kerja / total aktiva ( $\left.\mathrm{X}_{1}\right)$, laba ditahan / total aktiva (X2), EBIT (Earning Before Interest\&Tax) / total aktiva (X3), nilai pasar saham / nilai buku hutang $\left(\mathrm{X}_{4}\right)$, dan Penjualan / total aktiva $\left(\mathrm{X}_{5}\right)$. Dengan formula $\mathrm{Z}=1,2 \mathrm{X}_{1}+1,4 \mathrm{X}_{2}$ $+3,3 \mathrm{X}_{3}+0,6 \mathrm{X}_{4}+1,0 \mathrm{X}_{5}$. Hasilnya bahwa model Altman Z-Score dapat memprediksi kebangkrutan perbankan yang terdaftar di Bursa Efek Indonesia.

Hadi (2012) membandingkan antara model Altman Z - Score, model Zmijewski, dan model Springate, mana yang merupakan predictor delisting terbaik dari sampel berupa perusahaan manufaktur yang delisting dari Bursa Efek Indonesia periode 2003-2007. Hasil 
penelitian menyimpulkan bahwa model Altman $Z$ - Score merupakan prediktor delisting terbaik.

Berdasarkan teori yang telah dikemukakan di atas, maka hipotesis dalam penelitian ini adalah model Altman Z-Score tepat digunakan untuk memprediksi kebangkrutan pada perusahaan perbankan di Indonesia.

\section{METODOLOGI PENELITIAN}

\subsection{Obyek Penelitian}

Obyek penelitian ini adalah perusahaan perbankan yang terdaftar di Bursa Efek Indonesia yang delisting antara periode 2001-2012 dengan data laporan keuangan yang tersedia pada Indonesia Capital Market Directory (ICMD) minimal tiga tahun berturut-turut sebelum bank tersebut delisting.

\subsection{Teknik Pengumpulan Data}

Data yang dikumpulkan untuk penelitian ini adalah data sekunder. Data sekunder merupakan data yang didapatkan oleh peneliti secara tidak langsung dari obyek penelitian. Sumber data dalam penulisan skripsi ini adalah dari berbagai sumber buku, jurnal, majalah, dan sumber informasi terkait lainnya. Sedangkan sumber data yang akan diolah dalam analisis penelitian bersumber dari Indonesia Capital Market Directory dan situs www.idx.co.id.

\subsection{Model Penelitian}

Pengolahan data dalam penelitian ini akan dilakukan dengan bantuan program Excel dan program SPSS 18. Analisis yang digunakan untuk menggambarkan keadaan masingmasing kelompok perusahaan yang rugi atau tidak rugi melalui perhitungan dengan formula Altman, model analisisnya adalah sebagai berikut:

\section{$\mathrm{Z}=1,2 \mathrm{X} 1+1,4 \mathrm{X} 2+3,3 \times 3+0,6 \times 4+1,0 \times 5$}

Kriteria pengujian hipotesis dalam penelitian ini adalah:

\begin{tabular}{ll}
\hline Nilai Probabilitas & Arti \\
\hline $\mathrm{P}>0,05$ & Signifikan \\
$\mathrm{P}<0,05$ & Tidak Signifikan \\
\hline
\end{tabular}




\section{HASIL ANALISIS DAN PEMBAHASAN}

\subsection{Statistik Deskriptif}

Sampel yang digunakan dalam penelitian ini berjumlah 4 perusahaan perbankan yang delisting periode 2001-2012. Gambaran umum mengenai rasio keuangan masing-masing bank dapat dilihat pada Tabel 1.

Tabel 1

Uji Statistik Deskriptif

\begin{tabular}{|c|c|c|c|c|c|}
\hline & $\mathrm{N}$ & Minimum & Maximum & Mean & Std. Deviation \\
\hline Z3 & 4 & -.099 & .415 & .23600 & .228680 \\
Z2 & 4 & -.031 & .413 & .22650 & .190628 \\
Z1 & 4 & .014 & .387 & .20475 & .194969 \\
Valid N & 4 & & & & \\
(listwise) & & & & & \\
\hline
\end{tabular}

Dari tabel di atas dapat diketahui bahwa nilai rata-rata Z-Score perbankan pada tahun ketiga sebelum delisting sebesar 0,236. Nilai Z-Score terkecil pada tahun ketiga sebelum delisting dicapai oleh Bank Lippo sebesar -0,099. Nilai Z-Score terbesar pada tahun ketiga sebelum delisting dicapai oleh Bank Danpac sebesar 0,415.

Nilai rata-rata Z-Score perbankan pada tahun kedua sebelum delisting sebesar 0,22650. Nilai Z-Score terkecil pada tahun kedua sebelum delisting kembali dicapai oleh Bank Lippo sebesar -0,031. Nilai Z-Score terbesar pada tahun kedua sebelum delisting kembali dicapai oleh Bank Danpac sebesar 0,413.

Nilai rata-rata Z-Score perbankan pada tahun pertama sebelum delisting sebesar 0,20475. Nilai Z-Score terkecil pada tahun pertama sebelum delisting dicapai oleh Bank Pikko sebesar 0,014. Nilai Z-Score terbesar pada tahun pertama sebelum delisting kembali dicapai oleh Bank Danpac sebesar 0,387. Hal ini menunjukkan bahwa Bank Lippo selama tahun ketiga dan kedua sebelum delisting memiliki nilai Z-Score terendah, sedangkan pada tahun pertama sebelum delisting, nilai Z-Score terendah diperoleh oleh Bank Pikko. Di samping itu, selama tiga tahun berturut-turut sebelum delisting, Bank Danpac memiliki nilai Z-Score paling besar.

\subsection{Uji Hipotesis}

Pengujian hipotesis menggunakan Wilcoxon Signed Ranks Test yang dimaksudkan adalah metode Altman Z-Score tepat digunakan untuk memprediksi potensi kebangkrutan pada perusahaan perbankan di Indonesia. Hasil analisis dapat dilihat pada Tabel 2 berikut ini: 
Tabel 2

Uji Wilcoxon Signed Ranks Test

\begin{tabular}{|l|l|l|}
\hline \multicolumn{1}{|c|}{ Keterangan } & \multicolumn{2}{|c|}{ Signifikansi nilai } \\
$\mathbf{Z}$ & Simpulan \\
\hline Z-SCORE $(\mathrm{t}-3)-(\mathrm{t}-2)$ & 1,000 & Dapat digunakan \\
Z-SCORE $(\mathrm{t}-2)-(\mathrm{t}-1)$ & 1,000 & Dapat digunakan \\
\hline
\end{tabular}

Pengujian dilakukan dengan tingkat signifikansi $(\alpha)$ sebesar 0.05 atau tingkat kepercayaan $95 \%$. Berdasarkan hasil analisis Tabel 2 dapat dilihat bahwa variabel memiliki signifikansi nilai Z-Score yang lebih besar dari tingkat signifikansi $(\alpha)$ sebesar 0.05 , yaitu Z > 0,05 , sehingga hipotesis terdukung dengan data perbankan Indonesia. Hal ini berarti bahwa metode Altman Z-Score dapat digunakan di dalam menilai dan memprediksi potensi kebangkrutan perusahaan perbankan di Indonesia.

\section{SIMPULAN DAN SARAN}

\subsection{Simpulan}

Berdasarkan hasil penelitian mengenai analisis kebangkrutan pada perusahaan perbankan di Indonesia periode 2001-2012 menggunakan model Altman Z-Score, dapat ditarik kesimpulan bahwa model Altman Z-Score tepat digunakan untuk memprediksi kebangkrutan pada perusahaan perbankan go public di Indonesia. Hal ini menunjukkan bahwa model yang dikembangkan Altman mengenai Z-Score dapat mengakomodasi iklim dan kondisi ekonomi di Indonesia sebagai sebuah sistem peringatan dini akan potensi kebangkrutan, sehingga dapat dilakukan langkah perbaikan guna mencegah hal tersebut.

\subsection{Saran}

\subsubsection{Saran Bagi Pihak Perusahaan Perbankan}

Agar dapat diperoleh hasil Z-Score yang ideal yang sebaiknya dilakukan perusahaan perbankan adalah:

1) Menjual aset yang tidak produktif untuk melunasi kewajiban sehingga menyebabkan penurunan signifikan terhadap total utang dan total aset. Penurunan atas nilai total utang dan nilai total aset akan mengakibatkan seluruh rasio mengalami peningkatan.

2) Mengurangi kewajiban jangka pendek dengan lebih menggunakan sumber dana dengan jangka panjang sehingga akan meningkatkan jumlah modal kerja. Hal ini akan menyebabkan meningkatnya rasio modal kerja terhadap total aset. 
3) Meninjau kembali kebijakan mengenai pembagian deviden dan pembentukan laba ditahan agar rasio laba ditahan terhadap total aset meningkat.

4) Saat terdesak kebutuhan akan dana tambahan, diupayakan tidak membebani likuiditas dan solvabilitas perbankan dengan memperoleh dana tambahan dari pemilik modal yang mana memberikan biaya penyediaan lebih murah.

\subsubsection{Saran Bagi Peneliti Selanjutnya}

Peneliti sadar betul bahwa tidak ada satu model prediksi pun yang mampu mengakomodir seluruh kondisi dan iklim yang dihadapi perusahaan. Di samping juga perusahaan yang kian hari semakin berkembang mengikuti dinamika bisnis yang semakin kompleks. Untuk itu perlu dilakukan penelitian lanjutan dengan menggunakan model analisis kebangkrutan lain agar dapat dijadikan sebagai pembanding, ataupun penelitian lanjutan menggunakan pengembangan-pengembangan dan penyempurnaan terhadap model analisis kebangkrutan yang mungkin sekali akan hadir di masa yang akan datang.

\subsection{Keterbatasan Dalam Penelitian}

a) Sedikitnya jumlah sampel dan pendeknya periodisasi yang dihadirkan dalam penelitian ini mungkin memberikan hasil pengujian yang belum cukup mewakili kondisi dan iklim perusahaan perbankan di Indonesia.

b) Terdapat faktor-faktor lain penyebab terjadinya kebangkrutan suatu perusahaan, seperti tingkat inflasi, stabilitas politik dan keamanan, tingkat pertumbuhan ekonomi suatu negara, kebijakan fiskal dan moneter, tingkat upah tenaga kerja, dan banyak lagi faktor makro ekonomi yang berkontribusi dalam menunjang keberlangsungan suatu usaha. Hal-hal tersebut di atas tidak dihadirkan dalam pengujian ini, sehingga akurasi hasil penelitian ini akan semakin baik dengan dilakukannya penelitian dengan pengembangan berupa penambahan variabel-variabel di atas.

\section{DAFTAR PUSTAKA}

Altman, Edward. 1968. Financial Ratios, Discriminant Analysis And The Prediction of Corporate Bankruptcy. The Journal of Finance, Vol. XXIII, September, 589609.

Altman, Edward I. and Gabriele Sabato. 2005. Effects of the New Basel Capital Accord on Bank Capital Requirements for SMEs. Journal of Financial Service Research 28: $1 / 2 / 3,15-42$. 
Altman, Edward I. and Gabriele Sabato. 2007. Modeling Credit Risk for SMEs: Evidence from the U.S. Market. ABACUS, Vol. 43, No. 3, 332-357.

Altman, Edward I. 2005. An Emerging Market Credit Scoring System for Corporate Bonds. Emerging Markets Review 6, 311-323.

Altman, Edward I. and Herbert A. Rijken. 2011. Toward A Bottom-Up Approach to Assessing Sovereign Default Risk. Journal of Applied Corporate Finance, Vol. 23, No. 1, 20-32.

Altman, E.I. 2000. Predicting Financial Distress of Companies : Revisiting The Z-Score And Zeta Models. Updated From E. Altman, Financial Ratios, Discriminant Analysis and The Prediction of Corporate Bankruptcy. Journal of Banking \& Finance 1.

Bhagat, Sanjai, Nathalie Moyen, Inchul Suh. 2005. Investment and Internal Funds of Distressed Firms. Journal of Corporate Finance 11, 449-472.

Daftar Bank di Indonesia. Terpublikasikan Melalui Link: id.wikipedia.org/wiki/Daftar _bank_di_Indonesia. Diakses tanggal: 1 Agustus 2013.

Fakhrurozie. 2007. Analisis Pengaruh Kebangkrutan Bank dengan Metode Altman Z-Score terhadap Harga Saham. Skripsi. Terpublikasikan Melalui Link: repository.usu.ac.id/bitstream/123456789/31074/4/chapter\%2011.pdf. Diakses Tanggal: 1 Agustus 2013.

Fanny, Samaroni, Umaris. 2005. Analisis Kebangkrutan Model Altman Z-Score dan Springate. Skripsi Fakultas Ekonomi Jurusan Akuntansi. Universitas Budi Luhur. Terpublikasikan Melalui Link: riset.budiluhur.ac.id/wp-content/uploads/2012/06/AKUKEU_VOL-1_NO1_6.pdf. Diakses Tanggal: 1 Agustus 2013.

Frydman, Halina, Edward I. Altman, Duen Li Kao. 1985. Introducing Recursive Partitioning for Financial Classification: The Case of Financial Distress. The Journal of Finance, Vol. XL, No. 1, Maret, 269-291.

Ghozali, Imam. 2011. Aplikasi Analisis Multivariate Dengan Program IBM SPSS 19. Semarang: Badan Penerbit Universitas Diponegoro

Harahap, Sofyan Safri. 2008. Analisis Kritis Atas Laporan Keuangan. Jakarta: PT Raja Grafindo Persada.

Hunton, James E., Barbara Lippincott, Jacqueline L. Reck. 2003. Enterprise Resource Planning Systems: Comparing Firm Performance of Adopters and Nonadopters. Internantional Journal of Accounting Information Systems 4, 165-184.

Hadad, Muliaman D, Wimboh Santoso, Sarwedi, Hari Sukarno, Mohd Adenan. 2004. Model Prediksi Kepailitan Bank Umum di Indonesia. Jurnal Riset Biro Stabilitas Sistem Keuangan Bank Indonesia. Terpublikasikan Melalui Link: bi.go.id/NR/rdonlyres/734CC2E4-028F.../Kepailitanbank.pdf

Diakses Tanggal: 1 Agustus 2013 
Hadi, Syamsul dan Atika Anggraeni. 2008. Pemilihan Prediktor Delisting Terbaik (Perbandingan Antara The Zmijewski Model, The Altman Model, dan The Springate Model). Skripsi Fakultas Ekonomi Jurusan Akuntansi. Universitas Islam Indonesia.

Terpublikasikan Melalui Link: journal.uii.ac.id/index.php/JAAI/article/view/2263/2065

Diakses Tanggal: 1 Agustus 2013.

Iflaha, Diana Atim. 2008. Analisis Financial Distress dengan Metode Z-Score Untuk Memprediksi Kebangkrutan Perusahaan. (Studi pada Perusahaan Restoran, Hotel dan Pariwisata yang Listing di Bursa Efek Indonesia Periode 2003-2007). Skripsi Fakultas Ekonomi Jurusan Manajemen. Universitas Islam Negri Maulana Malik Ibrahim. Perpustakaan Pusat. Terpublikasikan Melalui Link: lib.uin-malang.ac.id/files/thesis/fullchapter/04610029.ps. Diakses Tanggal: 1 Agustus 2013.

Ikatan Akuntan Indonesia. 2007. Standar Akuntansi Keuangan. Jakarta: Salemba Empat.

Indonesia Stock Exchange. www.idx.co.id

Kamal, St.Ibrah Mustafa. 2012. Analisis Prediksi Kebangkrutan pada Perusahaan Perbankan Go Public di Bursa Efek Indonesia (dengan Menggunakan Model Altman ZScore). Skripsi Fakultas Ekonomi dan Bisnis Jurusan Manajemen. Universitas Hasanuddin Makassar.

Terpublikasikan Melalui Link: REPOSITORY.UNHAS.AC.ID/HANDLE/123456789/1051

Diakses Tanggal: 1 Agustus 2013.

Kasmir. 2008. Bank dan Lembaga Keuangan Lainnya. Edisi Revisi. Jakarta: PT Raja Grafindo Persada.

Kirkos, Efstathios, Charalambos Spathis, Yannis Manolopoulos. 2007. Data Mining Techniques for the Detection of Fraudulent Financial Statements. Expert Systems with Applications 32, 995-1003.

Nurdin, Irsyad. 2012. Peranan Analisis Metode Z-Score dalam Memprediksi Kebangkrutan Suatu Perusahaan dan Kaitannya Terhadap Harga Saham (Studi Pada Perusahaan Perbankan Yang Go Public Di Bursa Efek Indonesia ). Jurnal Skripsi Fakultas Ekonomi Jurusan Akuntansi. Universitas Siliwangi. Terpublikasikan Melalui Link: journal.unsil.ac.id/download.php?id=362. Diakses Tanggal: 1 Agustus 2013.

Pomerleano, Michael. 1998. The East Asia Crisis and Corporate Finances: The Untold Microeconomic Story. Emerging Markets Quarterly, 14-27.

Pomerleano, Michael. 2007. Corporate Financial Restructuring in Asia: Implications for Financial Stability. BIS Quarterly Review, September, 83-94.

Purwanti, Yulia. 2005. Analisis Rasio Keuangan Dalam Memprediksi Kondisi Keuangan Financial Distress Perusahaan Manufaktur yang Terdaftar di Bursa Efek Jakarta. Skripsi Fakultas Ekonomi. Universitas Islam Indonesia Yogyakarta. 
Terpublikasikan Melalui Link: research. mercubuana.ac.id/proceeding /2008061203142101312384.pdf. Diakses Tanggal: 1 Agustus 2013.

Sanusi, Anwar. 2011. Metodologi Penelitian Bisnis. Jakarta: Salemba Empat.

S. Munawir. 2002. Analisis Informasi Keuangan. Yogyakarta: Liberty Yogyakarta

Undang-Undang No.10 Tahun 1998 tentang Perbankan, Bank Indonesia.Jakarta.

Terpublikasikan Melalui Link:

bi.go.id/NR/rdonlyres/C7402D01-A030-454A.../uu_bi_1099.pdf

Diakses Tanggal: 1 Agustus 2013. 